\title{
Deslocamento Forçado na Colômbia e Políticas de Refúgio no Brasil: Gestão de populações em êxodo.
}

Recebido: 21-10-2018

Aprovado: 10-01-2019

Angela Mercedes Facundo Navia ${ }^{1}$

\section{Introdução}

Quando comecei a pesquisa de campo para a realização da minha tese doutoral sobre os processos de êxodo e refúgio de nacionais colombianos no Brasil, fui surpresa pela escassez de textos antropológicos sobre o tema. Se comparada com a produção de outros países, em que o refúgio tem sido objeto de profícuas reflexões sociológicas e antropológicas, as publicações sugeriam que no país, na época, este era um domínio de pesquisa da Ciência Política, das Relações Internacionais e do Direito. Com notáveis exceções as análises sobre o refúgio, nessas áreas disciplinares, pareciam estar inscritas numa antiga polémica sobre a presença ou ausência do Estado e sobre o que teria sido "deixado nas mãos da sociedade" em matéria de proteção a migrantes e refugiados, numa leitura de clara separação entre o Estado e a Sociedade (Mitchell, 2015, p.156) e suas competências em matéria de recepção e administração de populações em êxodo.

As menos abundantes pesquisas antropológicas, por sua parte, privilegiavam a indagação das condições de vida e processos de adaptação ao novo entorno cultural/nacional de grupos específicos de migrantes ou de refugiados. Essas etnografias, que definiram grupos ou sujeitos dentro deles como objetos de pesquisa, iluminaram importantes aspectos dos processos de negociação identitária, transformação cultural, criação de redes locais e transnacionais, assim como de manutenção de importantes vínculos com as comunidades de origem que inscreviam a migração dos sujeitos dentro de processos diaspóricos. Essas pesquisas também contribuíram para evidenciar

\footnotetext{
1 Professora adjunta do Departamento de Antropologia e do PPGAS da UFRN. Possui graduação em Antropologia pela Universidade Nacional da Colômbia (2003), mestrado em Ethnologie et Anthropologie sociale - École des Hautes Etudes en Sciences Sociales de Paris (2006) e doutorado em Antropologia social pela Universidade Federal do Rio de Janeiro (2014). Tem experiência na área de Antropologia, atuando principalmente nos seguintes temas: Refúgio e deslocamentos, gênero e produção de desigualdades sociais, fronteiras da nação, ações humanitárias, sentidos sociais dos sofrimentos. Brasil. Email: angelafacundo@hotmail.com
} 
etnograficamente antigas e novas formas de racismo e xenofobia, presentes nos diferentes locais de recepção. Não foi fácil, porém, achar trabalhos cujo foco fosse o processo mesmo da produção de fronteiras nacionais e sua naturalização no sistema contemporâneo, chamado por Liisa Malkki de "a ordem nacional das coisas" $(1995$, p. 8) ou das práticas de produção e gestão de categorias específicas e diferenciadas para lidar com populações pensadas como estrangeiras ${ }^{2}$.

Sem desconhecer as importantes contribuições que essas pesquisas realizaram para o entendimento da situação dos refugiados no Brasil, interessa-me nesse artigo, observando particularmente as propostas oriundas de outras áreas disciplinares, controverter a ideia de que a ausência de políticas de proteção a refugiados é equivalente a uma ausência de política de Estado a respeito da migração e do refúgio. Ou seja, espero mostrar que a precariedade das políticas públicas não é equivalente a uma ausência do poder do Estado para produzir sujeitos expulsáveis e/ou para filtrar aqueles que serão reconhecidos, daqueles que serão encaixados em outras categorias migratórias ou deixados de fora. Numa perspectiva antropológica, a partir do que poderíamos denominar de uma etnografia do Estado (Abrams, 2004; Das e Poole, 2004) gostaria de levar a sério o não fazer e o fazer precário como poderosas forças de ação política, expondo, de forma concreta, algumas práticas das tradições administrativas brasileiras na gestão de refugiados que foi possível identificar nesse empreendimento.

A pesquisa de campo que embasa essas propostas começou em 2011, quando me aproximei do tema durante meu doutorado no Programa de Antropologia Social do Museu Nacional da UFRJ, e se prolongou até 2016, alguns anos após a finalização do curso, especialmente em razão do desenvolvimento de um projeto de pesquisa de pós-doutorado, na Fundação Casa de Rui Barbosa, que também se ocupava de analisar a produção de categorias migratórias. Contudo, a maioria dos dados que analisarei nas próximas páginas correspondem à época da primeira pesquisa, informando sobre o contexto do universo institucional do refúgio, sobre a situação político-social brasileira e sobre as estatísticas produzidas entre os anos 2011 e 2014, mas, sempre que julgar necessário, atualizarei algumas informações, especialmente no que diz respeito aos números sobre o conflito na Colômbia.

\footnotetext{
${ }^{2} \mathrm{O}$ panorama em matéria de produção antropológica mudou desde então e hoje é possível achar um conjunto maior de textos que se aproximaram da reflexão sobre a administração contemporânea de refugiados na disciplina. Não é objetivo desse artigo realizar uma revisão da produção antropológica sobre o tema, mas gostaria de salientar alguns trabalhos que consegui mapear na época da pesquisa de doutorado e outros que foram realizados ou publicados posteriormente: Hamid (2012); Jardim (2003), Perin (2014) e Vieira (2017) e, de outras áreas, Moulin (2011).
} 
Etnografei diferentes locais, processos e encontros nos quais circulam, se envolvem e interatuam um amplo leque de funcionários do universo institucional do refúgio e pessoas migrantes, solicitantes de refúgio e refugiadas. Segundo a proposta de Trouillot (2001) estudei práticas, processos e efeitos de Estado, cujo resultado é a produção de sujeitos refugiados, ao invés de assumir essa categoria como um grupo dado. Quer dizer, considerei que uma etnografia sobre os refugiados é também, necessariamente, uma etnografia sobre os processos de classificação e sobre as tradições administrativas dos Estados que muitas vezes ultrapassam as intenções dos governos de turno. Em termos de Mitchell (2015 p. 146) me interessou indagar as técnicas que permitem que práticas materiais concretas de administração de migrantes, adquiram a aparência de uma prática abstrata e imaterial. Assim, me entrevistei não apenas com personas que encarnavam essas categorias migratórias, mas também com funcionários e funcionárias da Policia Federal, do Comité Nacional Para os Refugiados, do ACNUR, de Cáritas e de outras organizações da Sociedade Civil envolvidas no assunto. Sempre que me foi permitido pelas dinâmicas da pesquisa de campo, tentei acompanhar também os encontros desses sujeitos, as caraterísticas das interações e seus formatos.

A maioria desses encontros etnografados aconteceram em São Paulo e no Rio Grande do Sul, estados que além de receber refugiados pelas vias tradicionais de elegibilidade tinham também, na época, programas ativos de Reassentamento Solidário. Nesses estados, ademais das cidades capitais, visitei outros municípios do interior onde os "núcleos familiares" de reassentados foram localizados pelo programa. Realizei pesquisa também em Brasília e no Rio de Janeiro, locais importantes nas dinâmicas institucionais nacionais e que igualmente recebem solicitações de refúgio. Além de interações em contextos burocráticos, acompanhei eventos desenvolvidos pelas organizações da sociedade civil, pelo CONARE ou pelo Acnur, comemorações de datas significativas na área, passeatas, algumas audiências públicas relativas à migração ou refúgio e, do mesmo modo, acompanhei algumas pessoas nos seus trânsitos e espaços cotidianos de vida, tentando perceber também suas experiências como parte fundamental do entendimento do que produz o refúgio.

Minhas pesquisas previas sobre deslocamento forçado de populações na Colômbia, assim como o fato do Programa de Reassentamento Solidário brasileiro ter funcionado durante anos de maneira quase exclusiva para nacionais colombianos, me levaram a fazer um recorte metodológico envolvendo a nacionalidade como um marcador da pesquisa. Não considero a nacionalidade como um dado obvio e, pelo contrário, defendo que sua 
existência depende de práticas permanentes que reforçam ou apagam pertencimentos, representações, identidades, memórias, interpretações de eventos sociais e políticos, etc. Entretanto, a nacionalidade apareceu como um elemento presente e importantíssimo nas negociações dos processos de refúgio, especialmente quando se tratava de discutir a tão almejada "integração" à nação de recepção em termos de proximidade ou distância cultural. De fato, os colombianos foram frequentemente apresentados como facilmente integráveis, mas sempre quando comparados com outros grupos considerados como nacionalidades com menos facilidade de "abrasileiramento" (Seyferth, 2000).

De outra parte, marcar a nacionalidade me permitiu estabelecer um diálogo necessário entre os fatos sociopolíticos do país de origem das pessoas e a avaliação feita no Brasil sobre tais acontecimentos. A imigração, como defendido por Sayad (1991), envolve sempre um lugar de saída e não somente um lugar de chegada. Quando são abordadas apenas as condições das pessoas quando já classificadas como refugiadas no país de recepção há uma tendência a localizar "o problema" nos seus corpos e mentes (Malkki, 1995, p. 8) e não na opressão política ou na violência que produzem os deslocamentos de populações nos territórios. Mesmo com esse recorte pelo marcador social da nacionalidade, entendo que algumas das interpretações sobre as práticas de gestão de refugiados que serão apresentadas, são uteis também para descrever e analisar a realidade de grupos e indivíduos de outras nacionalidades que se encontram asujeitados em diversas relações com a institucionalidade brasileira do refúgio.

Nas próximas páginas, então, não realizarei uma descrição etnográfica da minha pesquisa, mas tentarei apresentar de forma resumida algumas das práticas de gestão de refugiados no Brasil na segunda década do século XXI, que foram identificadas a partir da análise da experiência de algumas famílias e indivíduos de nacionalidade colombiana, mas que podem iluminar a análise de outros trânsitos. Começarei apresentando brevemente a situação de deslocamento forçado interno e de refúgio na Colômbia, focando nas regiões que mais interessam para analisar a resposta brasileira, e passarei em seguida a discutir algumas das práticas de gestão desenvolvidas para as duas formas de recepção de refugiados pesquisadas: $\mathrm{O}$ refúgio pelas vias tradicionais - ou por elegibilidade $-\mathrm{e}$ o Programa Brasileiro de Reassentamento Solidário.

\section{Deslocamento Forçado e Refúgio}


É impactante a magnitude do drama do desterro forçado e do êxodo maciço de populações durante as últimas décadas na Colômbia. O Alto Comissionado das Nações Unidas para os refugiados (Acnur) e a Consultoría para los Derechos Humanos y el Desplazamiento (Codhes) ${ }^{3}$ estimam que o número de refugiados internos entre os anos 1985 e 2017 é de 7,3 milhões ${ }^{4}$. Em matéria de refúgio, na época da minha pesquisa, o documento Global Trends (2012) contabilizava 394.100 pessoas de nacionalidade colombiana refugiadas em diferentes países do mundo. Em março do mesmo ano Codhes aclarava que só uma parte do total de pessoas consideradas nas estatísticas teriam sido reconhecidas oficialmente como refugiadas pelo Acnur ou por algum governo nacional e que o 71,4\% (282.344 pessoas) encontrar-se-ia em condições "análogas ao refúgio", na "necessidade de proteção internacional", como "solicitantes de refúgio" ou "sem o status reconhecido". O cálculo realizado pela ONG é que $12 \%$ do total estimado dos colombianos no exterior são refugiados, o que equivaleria a dizer que "de cada 10 colombianos no exterior, ao menos um é refugiado ou encontra-se em "condições análogas ao refúgio" (Codhes, 2012, p. 34).

Diante desse panorama, incluindo a contundente documentação estatística, tanto do deslocamento forcado na Colômbia, quanto do número de refugiados colombianos no Equador, que para a época somava mais de 55 mil pessoas ${ }^{5}$, não foi motivo de surpresa tomar conhecimento da existência de um Programa de Reassentamento Solidário no Brasil, orientado para a recepção de nacionais colombianos ${ }^{6}$. Com uma conhecida relação de proximidade geográfica e cultural, assim como de trocas históricas entre os povos de ambos os países, a divisa entre o Equador e a Colômbia pode ser entendida numa dupla dimensão da fronteira que funciona ao mesmo tempo como controle, filtro e barreira e como ponte, conexão e comunicação (Anzaldúa, 2016).

\footnotetext{
${ }^{3}$ CODHES é uma ONG criada em 1992 com apoio internacional, que trabalha em pareceria com várias agências de cooperação e organismos multilaterais como o ACNUR. A organização trabalha com população deslocada e é uma importante produtora de dados a respeito. A ONG tem, além disso, uma forte capacidade de interlocução com a "comunidade internacional" e com amplos setores do governo e da chamada "sociedade civil organizada" na Colômbia.

${ }^{4}$ A população total da Colômbia na época da pesquisa, segundo as informações disponibilizadas pelo Departamento Administrativo Nacional de Estadística -DANE, era de 46.734 .845 pessoas. Segundo a mesma fonte, a população colombiana em 2018 é de 49.988.584. Informação disponível em $<$ http://www.dane.gov.co/reloj> Acesso em: 12 out. 2018.

${ }^{5}$ De acordo com o Ministério das Relações Exteriores e da Mobilidade Humana do Equador, o número total de refugiados cresceu e em 2018 contabilizaram 64.322 pessoas, sendo que 98\% delas (63.036) são de nacionalidade colombiana. Informação disponível em <https://www.cancilleria.gob.ec/informacion-sobrerefugio> Acesso em: 12 out. 2018.

${ }^{6}$ Algumas das pessoas que vieram para o Brasil nos primeiros grupos do Programa de Reassentamento Solidário foram previamente refugiadas na Costa Rica. Porém, depois o programa focou nos refugiados colombianos em território equatoriano.
} 
Muitas das populações da região sudoeste da Colômbia mantêm mais vínculos culturais, de parentesco e de comercio com algumas regiões do Equador, do que com regiões na Colômbia, incluindo o afastado centro político. Somado a isso, vale a pena salientar que o princípio de cidadania universal introduzido na constituição equatoriana em 2008, a pesar dos seus percalços e limites, foi um incentivo mencionado por muitas das pessoas refugiadas entrevistadas para decidir a rota de saída do seu país ou inclusive para optar por esse país como destino da fuga. Algumas dessas pessoas ou famílias escolheram a saída por esta fronteira até mesmo não morando em regiões próximas, nem tendo vínculos ou conhecidos. O Equador foi apresentado por algumas das pessoas com quem conversei como um local que lhes permitiria uma volta ao país de origem, relativamente rápida, caso a situação de violência melhorasse e conseguissem empreender o retorno, como era o desejo de alguns.

Junto com a conexão histórica de ambos os países e a política de cidadania universal, as dinâmicas do conflito colombiano também ajudam a explicar o alto número de refugiados no território vizinho. A região sudoeste da Colômbia tem sido palco de fortíssimos enfrentamentos entre grupos armados pelo controle territorial, assim como de uma intensa repressão aos movimentos sociais organizados, muitos deles marcados pelo seu pertencimento étnico indígena ou afrodescendente. Além da criminalização dos movimentos sociais por parte do Estado colombiano (Betancur, 2006; Ramírez, 2001) a estratégia paramilitar de repressão e espolio está ainda muito ativa e inclusive robustecida nos últimos dois anos. Segundo informações dos movimentos sociais da região e da Defensoria del Pueblo ${ }^{7}$, entre janeiro de 2016 e outubro de 2018 mais de 300 lideranças sociais foram assassinadas na Colômbia e, segundo Codhes, o 56\% delas pertencia a grupos étnicos. O departamento de Cauca lidera a posição com mais lideranças assassinadas e outros três departamentos das regiões sudoeste e oeste (Nariño, Valle del Cauca e Chocó) aparecem em terceiro, quarto e quinto lugar do ranking. O panorama da região piora substancialmente se além da criminalização, perseguição, assassinatos seletivos e a reaparição dos massacres, levarmos em conta a violência e o racismo estruturais, traduzidos em pobreza e falta de oportunidades, assim como o descumprimento dos Acordos de Paz, assinados em Havana entre o Governo Nacional e as Farc, que

\footnotetext{
7 Consultar, por exemplo, o site da Organização Nacional Indígena da Colômbia -ONIC$\langle$ http://www.onic.org.co/noticias $>$ e as matérias disponíveis no site da Defensoría del Pueblo $<$ http://defensoria.gov.co/es/nube/enlosmedios/7081/Colombia-en-dos-a\%C3\%B1os-282-1\%C3\%ADderessociales-y-defensores-de-derechos-humanos-fueron-asesinados.htm>
} 
incluíam uma política não militarizada de substituição de cultivos ilícitos na região, que até o presente não foi implementada.

Pois bem, diante da situação declarada de crise humanitária no Equador, um pequeno país com $283.520 \mathrm{~km}^{2}$ (aproximadamente a extensão territorial do Estado de São Paulo: $248.209 \mathrm{~km}^{2}$ ), com perto de 16 milhões de habitantes e que começou a virada do milênio recebendo um fluxo importante de refugiados colombianos, tornaram-se explicáveis as medidas adotadas a esse respeito na Declaração e Plano de Ação do México ${ }^{8}$. Para a época da promulgação do Plano o Brasil já tinha assinado (em 1999) um acordo com o Acnur para o reassentamento de refugiados. De fato, a Lei $n^{\circ}$ 9.474/97, no artigo 46, já previa o reassentamento e houve duas experiências prévias: em 2002 um grupo de 23 refugiados afegãos provenientes da Índia e do Iran e, em setembro de 2003, 16 refugiados colombianos provenientes da Costa Rica e do Equador (Moreira, 2012; Sampaio, 2006). Contudo, foi na reunião que deu origem ao Plano de Ação do México, quando o governo brasileiro propôs estabelecer, no seu território, "um programa de reassentamento regional para refugiados latino-americanos, marcado pelos princípios de solidariedade internacional e responsabilidade compartilhada" (Plano de Ação do México, Capítulo 3, $\mathrm{N}^{\circ}$ 3). Desde então, o programa de Reassentamento Solidário no Brasil estaria basicamente orientado para a recepção de refugiados colombianos e a única exceção foi o reassentamento de um grupo de refugiados de origem palestina que chegou em 2007 (Hamid, 2012).

Assim, com o andamento da minha pesquisa a verdadeira surpresa diante dessas informações foi conhecer o reduzido número de refugiados no território do gigante latinoamericano. Segundo o Ministério da Justiça do Brasil ${ }^{9}$ entre 2007 e 2017 foram reconhecidas 316 pessoas de nacionalidade colombiana pelas vias tradicionais do refúgio e 504 foram reassentadas no mesmo período. Esses números atualizados representam um pequeno aumento a respeito dos dados apresentados pela mesma fonte em 2014 quando os dois tipos de refúgio somavam apenas 741 pessoas, porém não há informações de quantas dessas pessoas permanecem no território brasileiro. Algumas famílias e indivíduos que conheci durante a pesquisa e com quem mantive contato despois de finalizada, por

\footnotetext{
${ }^{8}$ Declaração adotada pelo Acnur e por alguns países signatários, durante a reunião comemorativa do vigésimo aniversário da Declaração de Cartagena, realizada em Cidade do México, nos dias 15 e 16 de novembro de 2004

9 As informações estatísticas atualizadas foram consultadas no site do Ministério da Justiça e estão disponíveis em < http://www.acnur.org/portugues/wp-content/uploads/2018/04/refugio-emnumeros_1104.pdf> Acesso em: 12 out. 2018.
} 
exemplo, deixaram o Brasil e foram para outros países ou voltaram para a Colômbia ou para o Equador.

A pergunta que apareceu, então, é que tipo de tecnologias de governo e de formatos de ação e de gestão permitem que um imenso drama de deslocamento forçado na Colômbia se transforme no Brasil em um número reduzido de sujeitos (indivíduos e famílias) refugiados. Sujeitos sobre os quais, além disso, se constrói uma imagem bem-sucedida do refúgio que, por sua vez, ajuda a reforçar a imagem internacional do Estado-nação brasileiro como uma unidade caracterizada por seu espírito acolhedor, humanitário e solidário (Radhay, 2006).

\section{A Interpretação dos Números, uma Escassez Produtiva}

Há dimensões problemáticas na produção de estatísticas que merecem ser levadas em conta, sem desconhecer, claro, sua importância social em processos de disputa de interpretações de fenômenos sociais como é o caso dos deslocamentos forçados e das migrações, nos quais saber de quantas pessoas está se falando e conhecer suas caraterísticas pode fazer toda a diferença no seu atendimento. Podemos pensar, por exemplo, na dificuldade de traduzir em números realidades sociais complexas como as guerras e os conflitos que dificilmente podem ser resumidos em indicadores e que muitas vezes são por eles desencarnados de seus efeitos mais marcantes na vida social, caracterizados pelas emoções, a intensidade das experiências vividas por sujeitos de carne e osso e pela importância social dada à individualização e personificação das experiências contabilizadas.

De outra parte, também existe o risco de fazer coincidir forçosamente a existência de um fenômeno social com o momento de sua enunciação por meio de sua evidência estatística ou de "criar o problema social" quando divulgado. De maneira ilustrativa, no Brasil, os momentos de publicação de números sobre o refúgio, durante os anos da minha pesquisa e inclusive depois, costumavam ser períodos de alarme para alguns setores sociais que "descobriam" ou "redescobriam" a presença, para eles exagerada, de estrangeiros no território nacional. Para outros setores o motivo do alarme era o oposto, quer dizer, a constatação da baixa taxa de reconhecimento, acompanhada de uma crítica à falta de investimento em políticas que garantissem práticas concretas de reconhecimento e acolhimento. Fica claro que a produção de estatísticas é uma prática social, realizada e

direcionada por e para atores concretos, afetada pelos seus diversos ordenamentos 
hierárquicos e cujos efeitos se inscrevem no mesmo universo que pretendem traduzir. A produção de números está longe de prover uma informação objetiva que finde as divergências sobre determinado fenômeno ou que garanta uma interpretação unívoca da realidade que se pretende documentar.

A partir de 2014 o Conare produziu documentos unificados com dados sobre refúgio que facilitaram o acesso às informações consideradas oficias. Porém, não era esse o panorama dos anos precedentes em que números discordantes eram publicados com poucos dias de diferença nas páginas do governo ou das suas agencias aliadas, permitindo interpretações diferentes e até mesmo contraditórias a partir dos mesmos dados. A obliteração da fonte que oferecia cada número, os números discordantes e as omissões a respeito de como eram feitas as interpretações, permitiam que estas fossem mobilizadas de maneiras muito diversas. Com os mesmos dados, em que algumas vezes era enunciado o número reduzido de refugiados, era produzida também uma imagem de excesso, habitualmente ecoada pela mídia.

Contudo, um número chamou particularmente minha atenção. Diversos dos agentes que atuam no universo institucional do refúgio, desde o diretor do Conare na época, até funcionárias e funcionários das ONGs, costumavam mencionar as 77 nacionalidades diferentes de refugiados que alberga o Brasil. Essa menção era feita em diversos cenários: entrevistas, eventos comemorativos, notas e coletâneas de imprensa, documentos de divulgação, entrevistas com a pesquisadora, etc. O número foi aumentando conforme o passo dos anos e da última vez que escutei a menção, em um evento comemorativo do dia mundial do refugiado, já se falava em 87 nacionalidades diferentes. A enunciação do caráter grandioso das 77 ou 87 nacionalidades permitia, ao mesmo tempo, opacar outras informações marcadas pela escassez. O efeito de opacidade funcionava até o ponto de que em diversos cenários a enunciação da abundância de nacionalidades dispensava a menção do número total, e magro, de refugiados.

Quando indagado nas entrevistas sobre a razão do baixo número de refugiados no Brasil, houve uma mutua inculpação das partes envolvidas. Referidas ao Programa de Reassentamento Solidário, por exemplo, as explicações sobre o número de reassentados orbitavam entre a limitada capacidade de recepção da sociedade civil, que os funcionários do governo salientavam; a falta de investimento concreto do governo nacional, apontada pelo Acnur e Cáritas e o desinvestimento progressivo do Acnur no programa, destacado pelos funcionários de governo e pelas ongs. As mutuas inculpações criavam uma fita de moebius que podia ser andada em qualquer direção sem encontrar o ponto para resolver a 
contradição das explicações. Quando questionada a baixa quantidade de refugiados que chegam pelas vias tradicionais, além da enunciação de uma fronteira supostamente "distante e sem conflito" entre o Brasil e a Colômbia e da julgada melhoria nas condições políticas no vizinho país que teriam levado ao refinamento da avaliação das solicitações, muitos dos problemas de funcionamento em relação aos documentos, vistos, tempos de espera, processos de reconhecimento, etc., também encontraram uma justificativa suficiente nesse repertório interno de mútuas acusações e desobrigações que tem como base a contradição das partes (Herzfeld, 1992, p. 46).

Em uma outra linha argumentativa, as explicações sobre o baixo número de refugiados foram positivadas por muitos dos funcionários e funcionárias entrevistados. Segundo algumas dessas conversações, o diferencial entre o Brasil e o Equador, em termos de proteção, era que o primeiro garantia a segurança das pessoas por meio de um apurado processo seletivo, em quanto o Equador seria aquele local de caos e indiferenciação que teria permitido a mistura de algozes e vítimas, de migrantes econômicos e refugiados, de "verdadeiros" e "falsos" refugiados, etc. Segundo essas explicações, a parca presença de refugiados no Brasil não apenas não seria um dado negativo, mas uma amostra da competência técnica do processo que seleciona os "verdadeiros refugiados" ou que reassenta somente aqueles cujo perfil se adeque às caraterísticas do programa de reassentamento.

Essa escassez positivada, que produz uma imagem de controle e competência técnica é também reforçada pela ideia de que não se trata de receber muitos, mas de recebê-los bem. Frase que também foi repetida, quase com as mesmas palavras, por diferentes atores institucionais. Essa explicação, que circula como uma razão legítima entre várias das partes envolvidas no reconhecimento de refugiados, pode oferecer pistas sobre a preferência na utilização de outras categorias migratórias ou sobre a insistência no mesmo processo seletivo individualizado em momentos que exigiam respostas de proteção menos restritas e mais abrangentes. Por exemplo, no caso dos grupos que têm chegado no Brasil nos últimos anos em quantidades mais expressivas como o caso dos haitianos, dos sírios ou, o mais recente, dos venezuelanos.

Segundo a leitura sobre as bondades de receber poucos, mas recebê-los bem, cada história bem-sucedida é uma grande vitória, assim, se em alguns momentos os refugiados são apresentados como um grupo indistinto de sujeitos sofredores, em outros momentos a vida de alguns deles é escrutada, valorizada, individualizada e apresentada para espetadores e telespectadores como uma amostra viva desse exercício de proteção. 
Destarte, o efeito produzido com a interpretação positivada dos números é habitualmente potenciado com a apresentação de imagens e/ou depoimentos comovedores de pessoas refugiadas, tal como aconteceu na maioria dos eventos que acompanhei durante minha pesquisa de campo.

Além do apelo à emoção do espectador (Bolstansky, 1993), a apresentação de depoimentos de pessoas classificadas como refugiadas reforça a credibilidade social das instituições e organizações envolvidas na classificação e gestão de refugiados, mostrando que não apenas produzem números, mas também têm o poder de mobilizar os corpos das pessoas para acompanhar esses eventos e para contar suas experiências. Há nessa prática de individualização uma semelhança com o poder pastoral proposto por Foucault que, na leitura de Vianna (2002, p. 42) permite pensar essas ações não como uma imposição unilateral de formas repressoras, mas como uma "produção de soluções administrativas" que operam graças à existência de interesses mútuos em "níveis diferenciados de autoridade". A virtude da obediência de cada ovelha do rebanho, lembra a autora nessa leitura foucaultiana, é também uma virtude do pastor, conseguida mais pelo conhecimento "não de ovelhas genéricas, mas do estado de cada ovelha" (Vianna, op. cit., p. 43). Saber escolher e escolher bem são ações que fazem parte desse conhecimento que tem o poder de oferecer ou negar o pertencimento ao um novo Estado-nação e de decidir os termos em que será feito.

\section{Selecionar Sujeitos}

A prática de seleção, constituinte dos processos de produção e gestão de refugiados, fica tal vez mais clara no reassentamento do que no refúgio por elegibilidade. Contudo, nos dois tipos há práticas de seleção, classificação e diferenciação de sujeitos, de experiências e de sofrimentos. No caso do reassentamento a ação de seleção se faz mais evidente na medida em que ele não é uma obrigação dos estados, mas uma decisão discricionária que, por conseguinte, permite que cada governo decida e planeje a quantidade, a frequência e o perfil das pessoas que serão recebidas. No programa brasileiro a decisão sobre esses aspectos é apresentada como uma deliberação tripartite na que participam representantes do governo, da sociedade civil organizada e do Acnur ${ }^{10}$. Sob o nome de "missão de seleção" é conhecida a viagem que os representantes dessas instancias realizam para o Equador com o intuito de entrevistar pessoas ou famílias - previamente selecionadas pelo

\footnotetext{
${ }^{10}$ Esse modelo tripartite é em si mesmo um formato de ação que influencia as práticas aqui analisadas, porém não vou me deter nesse artigo sobre o assunto que pode ser consultado em outro texto (Facundo, 2017).
} 
Acnur como candidatas com um perfil encaixável no definido para o programa brasileiroe de escolher quais delas serão efetivamente transferidas.

Algumas das pessoas que foram selecionadas como candidatas e posteriormente reassentadas, comentavam que parte das estratégias para serem escolhidas consistia em frisar a iminência da extinção da sua vida física. De nada adiantava, segundo elas, expor a calamidade social e política das suas vidas, pois a maioria dos refugiados no Equador estaria nas mesmas circunstâncias. O diferencial para serem escolhidas estava na iminência da sua extinção física. De outra parte, era importante não deixar transparecer que se conhecia a opção do reassentamento. As autoridades do refúgio também frisaram que o programa é uma oferta e que não pode ser demandado, mas apresentado como uma opção. $\mathrm{O}$ fato de que o reassentamento seja uma oferta colabora com o estabelecimento de relações de gratidão das pessoas que presumem ou sentem que foram escolhidas e salvas no meio de um purgatório de sofredores. Nesse mecanismo a obrigação de gratidão e a dívida suposta do refugiado com a comunidade que o acolhe é ainda mais evidente do que no caso dos refugiados espontâneos, para quem o refúgio, em última instância, é um apelo à legislação internacional e pode ser pensado como uma ação inscrita no plano dos direitos.

Funcionários e funcionárias que trabalhavam na época da pesquisa, ou já haviam trabalhado, como agentes das ONGs que participam da seleção -ONGs de alguma maneira vinculadas à igreja católica- expressaram seu incômodo com o nome utilizado para a Missão de Seleção. Notadamente dois religiosos católicos e dois agentes "laicos" da rede de ONGs estavam inconformados com essa imagem de escolha de pessoas. Porém, é efetivamente a prática empreendida durante essa viagem e durante os processos posteriores de avaliação dos casos na reunião plenária do Conare. Essa imagem de salvação de corpos e de almas sofredoras no meio de um abismo confuso de seres condenados, que irremediavelmente nos remete à iconografia cristã do purgatório, lembra novamente de alguns dos princípios do que Foucault (1988) chamou de poder pastoral, discutidos acima.

Além de considerar a iminência da extinção física das pessoas, quer dizer, de classificar e hierarquizar as ameaças à vida segundo os ritmos (mais rápidos, menos rápidos, lentos) e segundo os tipos (miséria, pobreza, falta de oportunidades, ameaças, doenças, atentados, etc.), também é considerada a "capacidade de acolhida da sociedade civil”. Ademais da leitura positivada de uma recepção moderada de pessoas, que já foi mencionada, a avaliação feita por quem planejam e coordenam o programa é a de que as pessoas que chegam não devem ficar juntas para não impactar as comunidades locais. $\mathrm{O}$ impacto é medido em termos das demandas dos estrangeiros em relação a emprego, saúde, 
moradia e educação, mas, foi frequentemente evocada a diferença cultural como um elemento que devia ser igualmente considerado e trabalhado pelo programa. Em repetidas ocasiões escutei agentes de reassentamento apontarem a importância de evitar a formação do que chamaram de "guetos". Em trabalhos sobre a história de outros processos migratórios no Brasil, Giralda Seyferth (2000) analisou os ideais de integração e aculturação da época que viam na presença estrangeira, culturalmente diferenciada, uma ameaça para a união da nação e buscavam combater os "quistos" estrangeiros. Chama a atenção que contemporaneamente, sob a égide do paradigma multiculturalista, esse temor do gueto esteja presente na sensibilidade dos funcionários e seja uma razão válida para vincular os sujeitos reassentados a determinados territórios.

Para o reassentamento de colombianos, ainda, foi mencionado o perigo de ficarem juntas pessoas ou famílias pertencentes a "lados opostos da guerra", somando assim mais argumentos para o uso da estratégia de dispersão territorial. Esta estratégia, que busca localizar às pessoas em locais distantes uns dos outros, foi utilizada inclusive em estados do Brasil em que a imensidade das cidades, como no caso de São Paulo, dificilmente permitiria que um reduzido número de pessoas alterasse significativamente as dinâmicas locais. Os locais escolhidos, em geral, foram pequenos municípios próximos das cidades capitais que ofereciam limitadas opções em matéria de lazer, educação e emprego. Pelo menos foram essas as queixas mais frequentes das famílias reassentadas com as quais falei, para quem a escolha do local onde elas foram morar era eloquente sobre o tipo de vida que o programa almejava para elas, sem grandes expectativas de educação superior e com empregos nas áreas mais básicas de serviços ou da construção civil.

A percepção das famílias não distava muito das explicações que me foram oferecidas pelos administradores e funcionários do programa. Algumas das pessoas que acompanharam o programa do início, comentaram que as experiências pioneiras com grupos de outras nacionalidades que tinham um perfil sociocultural elevado, haviam deixado como aprendizado a inconveniência de reassentar grupos desse tipo. As expectativas sociais exigentes e o estilo de vida de camadas médias, levariam ao descontentamento permanente das pessoas com as características materiais do programa: as casas, a mobília, o tipo de empregos disponíveis, etc. A decisão para contornar essas situações foi combinar a enfática enunciação da falta (de recursos, de tempo, de pessoal) no momento da entrevista de seleção com a escolha de pessoas com "baixo perfil" (referindo-se basicamente a seu nível educativo e a seu suposto pertencimento de classe) de quem supunham que não teriam grandes expectativas sobre a "nova vida no Brasil". 
Também se incorporou um cálculo que antecipava um mal-estar no momento final dos auxílios econômicos, de modo que usualmente se estabeleceu um tempo possível de benefícios, mas se ofereceu um menor para ter opção de negociação.

Outra caraterística que apareceu com muita clareza durante a análise do programa, foi a preferência pelo reassentamento de famílias heterossexuais com filhos em idade escolar. Os chamados núcleos familiares, na terminologia oficial. Sem tanta representatividade numérica, outro tipo de famílias e homens sós também foram reassentados, não obstante, a maioria das pessoas que conheci durante a minha pesquisa de campo formavam famílias de quatro integrantes: um casal heterossexual em idade para trabalhar, com dois filhos, geralmente uma menina e um menino. As pessoas reassentadas mencionaram que essa informação também circulava entre os interessados e candidatos ao reassentamento no Equador avisando de maneira informal que o programa brasileiro buscava famílias conjugais com descendência. Dito formato é parecido com aquele que representa a "família brasileira" nas imagens de programas de governo destinados aos setores de baixa e média renda no Brasil. Justamente as camadas onde se espera que sejam integradas as famílias reassentadas. Essa escolha do programa permite salientar que os processos de governança das populações são também processos de generificação que afirmam e reproduzem normas e formatos sociais a esse respeito.

Um dos pressupostos associados a esse formato é que cada um dos integrantes do núcleo familiar estabelecerá determinadas relações em razão do gênero, da idade, do seu lugar na família e das obrigações sociais que esse lugar significa, nos espaços destinados para cada um deles (escola, trabalho, lar, igreja, etc.). Espaços que, não sobra dizer, se baseiam em um esquema bastante convencional de gênero e geração que reforça por sua vez a ideia de que a nação é heterossexual. Com a preferência por esse tipo de família, heterossexual e nucleada -que está se repetindo em outros programas de proteção, como no caso da interiorização de refugiados ou migrantes venezuelanos- não apenas se excluem outros tipos de família, mas também outros vínculos de parentesco que frequentemente têm importância existencial para as pessoas. Muitos dos sujeitos que aceitaram o reassentamento deixaram para atrás mães, pais, avos, avôs, tias, tios, primos, sobrinhas, etc. $\mathrm{O}$ abandono desses vínculos em não poucas ocasiões foi descrito como desestruturador e transformou-se em uma nova etapa do exilio que requeria deles grandes esforços para tentarem juntar de novo essa constelação de relações que para eles definia a família.

\section{Produzir Refugiados}

Revista de Estudos e Pesquisas sobre as Américas V.13 N.1 2019 ISSN: 1984-1639 
A possibilidade de escolher o perfil das pessoas reassentadas contrasta com a impossibilidade de conhecer com antecedência as caraterísticas das que realizarão uma solicitação de refúgio pelas vias tradicionais. Mas, isso não quer dizer que não há mecanismos de controle e de filtragem nessa forma de proteção. Algumas etnografias sobre as relações institucionais com outros grupos de migrantes, também com recorte de nacionalidade, como o caso dos haitianos (Vieira, 2017) ou dos sírios, reforça a tese de que a espontaneidade na chegada de grupos de pessoas demandando proteção não tem uma tradução direta no número de reconhecimentos e nem sequer no número de solicitações que são ativadas. Entre o êxodo e os trânsitos das pessoas e seu possível reconhecimento como refugiadas há um amplo universo burocrático que regula as formas de entrar e de sair e marca as caraterísticas das estadas e dos pertencimentos. Um percentual muito baixo das pessoas com necessidade de proteção no mundo consegue chegar até os escritórios das instituições dos estados nacionais, mas, inclusive aqueles que alcançam, devem passar por detalhados e sinuosos processos burocráticos para obter um reconhecimento e um novo pertencimento, mesmo que restrito, a um estado-nação.

A rígida separação e diferenciação entre migrantes econômicos e refugiados é a base dos processos para a concessão do status de refugiado, distinção que é resumida na fórmula de um fundado temor de perseguição. No Brasil, a diferença de outros países que têm utilizado formatos jurídicos e julgamentos públicos para a toma de decisão, o mecanismo é alimentado pela palavra dos sujeitos em formatos de declarações, entrevistas e avaliação dos seus comportamentos. Entende-se que as narrações, que são demandadas em diversos momentos do processo, são um exercício de transparentar a verdade ou de fazer que ela abrolhe do seu interior. Essa ideia está baseada, por sua parte, em outra presunção segundo a qual as tecnologias de governo e a competência dos profissionais que -em relações sociais altamente codificadas, como as entrevistas ou as declarações-, obtêm essas narrações, são capazes de cavar no sujeito para obter essa verdade e interpretá-la. Os gestos, as pausas, as emoções que acompanham cada parte dos relatos são assumidos como signos visíveis da inscrição da verdade objetiva na subjetividade profunda do narrador.

A fragmentação e classificação da vida dos solicitantes não faz muito sentido para as pessoas que passaram por experiências que misturam inextricavelmente esses dois registros: pobreza (migrante econômico) e perseguições (refúgio); e para quem, de fato, essas duas dimensões são mutuamente constituintes. Porém, nos formatos de narração exigidos nas práticas de governança do refúgio, e na interpretação desses relatos, exclui-se a possibilidade de expor a multicausalidade dos eventos. A produção da história vai 
exigindo privilegiar somente as causas que possam ser produzidas com o formato de terror e perseguição que fundaria o temor do sujeito solicitante, selecionando alguns dos fragmentos possíveis para lhe dar um sentido unívoco à história e obliterando a complexa trama de experiências que podem chegar a configurar um êxodo. A maldade cotidiana não é ponderada (desigualdade, pobreza, fome, falta de recursos), é a maldade extraordinária, que tanto desumaniza quanto singulariza os sujeitos (tortura, destruição de cidades, ameaças, bombardeios, massacres), aquela que movimenta a bondade organizada mundialmente na figura do refúgio.

Funcionários e funcionárias comprometidos com a luta pela proteção cada vez melhor e mais abrangente de refugiados e que fazem parte do universo institucional brasileiro, têm criticado esse formato de seleção e ainda apontado a necessidade de criar mecanismos mais transparentes para o reconhecimento do status de refugiado. Também organizações internacionais, e o próprio Acnur, têm chamado a atenção sobre a dificuldade de distinguir entre migrantes econômicos e refugiados nos trânsitos coletivos e maciços. Porém, mesmo com essas boas intenções e com os avanços nos debates e pactos internacionais, a realidade no Brasil continua sendo marcada por essa procura de exorcizar o fantasma do migrante. Paradoxalmente, a participação da sociedade civil no processo de seleção que, a princípio, deveria representar uma vantagem para os solicitantes se comparado com outros países sem tal acompanhamento, pode se tornar em uma forma de verificar sua palavra por meio do contraste permanente entre a multiplicidade de narrações e descrições que são exigidas.

Os processos seletivos baseados na interpretação de diversos tipos de declarações e depoimentos partem ademais da ideia de que existe uma coerência entre experiência, memoria e narração. Argumentando no sentido contrário, as etnografias de vários autores que trabalharam em contextos de violência e de produção oral de depoimentos após etapas de intensos conflitos sociais (Das, 2008; Cho, 2008; Pollak, 1990), apontam para a desintegração do tempo progressivo e cronológico como caraterística da lembrança traumatizada e para a impossibilidade expressa por muitos sujeitos de realizar reconstruções por meio da palavra daquilo que foi vivido na experiência corporal e que atinge um limite da linguagem para expressá-lo. Assim, o que acontece na relação social das entrevistas é menos uma exteriorização do interior do sujeito ou da verdade de suas experiências passadas e mais uma produção conjunta e organizada de uma história de dor que possa ser considerada digna de refúgio, em contraste com as dores pagãs do migrante. $\mathrm{Na}$ mesma linha de argumentação das pesquisas citadas, na sua qualidade de montagem, 
essas produções narrativas somente têm sentido se entendidas em seu contexto de produção conjunta, na interação com cada um dos sujeitos que integram como interlocutores essas cenas sociais, em lugares diferenciados de poder. Buscar uma única versão da história dos sujeitos que se repita sempre da mesma maneira é tentar negar as relações de poder que configuram esses momentos, assim como os limites e jogos da linguagem e da memória, intrínsecos da experiência humana.

Vale a pena levar em conta que os tempos de espera para que as diferentes entrevistas e declarações aconteçam costumam ser tempos longos e fazem parte também dessas técnicas de gestão que produzem subjetividades especificas. A declaração na Polícia Federal e a entrevista com as ONGs representantes da sociedade civil acontecem com relativa celeridade, a depender dos ritmos das instituições em cada cidade. Porém, a entrevista com os representantes do Conare costuma demorar e esse encontro é imprescindível para completar o processo de solicitação. Serão os pareceres das duas entrevistas, que levam em conta também as declarações feitas na Polícia Federal, os que determinarão as possibilidades concretas das solicitações de refúgio receberem um parecer definitivo na reunião do Grupo de Estudos Prévios do Conare e de serem oficialmente deferidas ou indeferidas na sua reunião plenária. Durante o tempo de espera as pessoas ficam vinculadas burocraticamente às ONGs que controlam os processos de documentação e que cuidam também dos programas sociais que incluem eventuais apoios financeiros, cursos de português, assistência psicológica e social. Serviços fundamentais para as pessoas que chegam sem recursos, nem redes.

Foi interessante perceber que o tempo transcorrido nesses processos cobra um valor em si mesmo, como apontado em outros trabalhos (Facundo, 2017). Não desistir, esperar o desfecho de cada etapa, demostrar a "verdadeira necessidade de permanecer" não apenas nas entrevistas, mas na interação cotidiana com outros funcionários das instituições, e dos programas de proteção, têm efeitos na produção moral dos sujeitos e no reforço da suposta veracidade da sua história de refúgio. A interação permanente mediada por tempos e ritmos - um voltar amanhã, passado amanhã, o mês que vem; esperar sua vez; acatar recomendações de paciência, solicitações de compreensão dos limites e precariedades dos programas; ir se acostumando com marcações sutis, mas efetivas de autoridade, etc.caracteriza boa parte das relações entre administradores e administrados nos escritórios das ONGs, como magistralmente descrito por Perin (2014). O tempo apareceu nas conversas com solicitantes, refugiados e reassentados referido às etapas que precisaram atravessar em situação de inferioridade, quer dizer, sem ter o controle das decisões a serem tomadas 
sobre suas vidas, nem dos recursos que ajudassem a sobrelevar a espera. Como apontado em trabalho com Vianna, a administração do tempo produz e reforça assimetrias. Os sujeitos ficam em situação de dependência de instâncias que têm o controle sobre os recursos e o poder de administrá-los "de forma que parece sempre escassa, mesquinha e irregular" (Vianna e Facundo, 2015. p. 49).

O vínculo dos sujeitos com os escritórios das ONGs também é eloquente sobre outro tipo de técnicas de governo de populações em êxodo. Mesmo apresentado como um mecanismo não obrigatório no processo de solicitação, o contato com essas instituições terminou se mostrando difícil de contornar. Algumas pessoas conseguiram ativar a solicitação de refúgio nas unidades da Polícia Federal em cidades onde não há presença das ONGs mas, de qualquer modo, foram registradas e cadastradas em um dos escritórios para fins administrativos e de controle e facilitação dos procedimentos, inclusive argumentando a necessidade de proteger os refugiados e solicitantes das possíveis negligencias de outros organismos envolvidos no reconhecimento ou na renovação de documentos. Os funcionários defendem que o cadastro dos processos dos solicitantes não obriga estes últimos a se deslocarem do lugar de residência. Contudo, as histórias de algumas pessoas entrevistadas parecem contradizer essa suposta inocuidade do local de registro, descrevendo exigências de se apresentar nos escritórios em diferentes momentos do curso administrativo e a necessidade de manter contatos presenciais com os funcionários para conseguir conclui-lo.

O fato desses escritórios estarem localizados em cidades capitais e a forma regionalizada do atendimento foi explicada pelas autoridades do universo administrativo em função da concentração do número de solicitantes em alguns municípios do território nacional. Segundo elas, nas cidades onde há maior número de solicitações e de refugiados reconhecidos, existiria também uma ONG em convênio com o Acnur e o Conare. No entanto, a explicação contém uma parte da causa. Mesmo que alguns locais mais conhecidos internacionalmente, ou com mais redes de migrantes atraiam grande parte das populações, a focalização dos postos administrativos de refugiados contribui para que as pessoas prefiram ou devam se estabelecer perto dos lugares de atendimento, pelo menos durante o tempo que durar essa relação de múltiplas dependências com as instituições.

Finalmente, nessa distribuição espacial dos locais de atendimento há também pistas sobre a importância de escolher não apenas os sujeitos, mas também os locais para produzir uma imagem de refúgio e de refugiados que alimente a ideia da capacidade brasileira de cuidar e proteger sujeitos perseguidos em outros países. Por exemplo, a 
decisão de não localizar as pessoas em algumas áreas rurais brasileiras e de encerrar o programa de reassentamento no Rio Grande do Norte baseou-se no argumento da impossibilidade de oferecer condições "adequadas para a integração" naquela região. Essas condições são elencadas em termos de escassas redes de apoio, infraestrutura precária, baixa oferta de serviços e possibilidades mínimas de emprego. Porém, outras circunstâncias não foram citadas, como os problemas de acesso e uso da terra, de permanência em condições seguras em suas propriedades, as possibilidades de sobrevivência de pequenas unidades de produção rural, a garantia de segurança alimentar, entre outras. Essas condições são similares às que, muitas vezes, provocam o êxodo das pessoas na Colômbia, para além da existência frontal de ameaças e espólio, das quais de fato o Brasil também não está isento, nem sequer no seu Sul "desenvolvido". É possível então entender algumas das configurações que levaram a que as políticas contemporâneas do refúgio no Brasil tenham se baseado num formato urbano de recepção de refugiados espontâneos e reassentados, concentrando para isso seus pontos de atendimento e seus recursos em algumas das cidades do Sul e do Sudeste.

Com as análises propostas e as possíveis críticas sobre algumas das formas de gestão apresentadas não se trata de desconhecer a importância que para as pessoas refugiadas e reassentadas têm esses programas. De fato, boa parte das reclamações por elas elencadas visam o aprimoramento e extensão da assistência e do acompanhamento das instituições e não da sua extinção. A proposta desse texto está muito mais orientada para percebermos que as pessoas mais atingidas pelo espolio e as atrocidades da guerra continuam não sendo contempladas nesses mecanismos de proteção, em boa parte por conta dos refinamentos das técnicas e práticas de seleção, produção e gestão de sujeitos em êxodo. Finalmente, o texto propõe também sermos conscientes que nos nossos programas sociais mais bondosos misturam-se valores essenciais para a vida coletiva como a solidariedade, a capacidade de empatia e comoção e a produção dos direitos como lutas continuas na procura do bem comum; mas, também misturam-se tradições administrativas que produzem e mantem assimetrias, que se baseiam em julgamentos morais culturalmente referenciados e que reforçam as desigualdades planetárias produzidas por diversos marcadores sociais da diferença.

\section{Considerações Finais}


Com o resumo de algumas das práticas e formatos de gestão de refugiados no Brasil, tentei chamar a atenção sobre os diferentes tipos de poderes, incluindo o poder do Estado, que estão em jogo nos mecanismos, mesmo que precários, de gerenciar as populações em êxodo. Como sugerido por Souza Lima (1995) sobre o que ele tem chamado "poder tutelar" -nas análises das ações do poder estatal no Brasil sobre os povos indígenas e sobre seus territórios- há formas de ação que, mesmo podendo ter origens não estatais, em um momento determinado se condensam em "um centro social e geográfico de poder imaginado como nacional" (Souza Lima, 2012, p. 799). Segundo o autor, essa concentração, como no caso descrito das ONGs, é dirigida por especialistas em “imaginação e administração de coletividades" (Ibidem). No caso que interessa nessa reflexão, o comando de especialistas chegou por meio de agências transnacionais como o Acnur, cuja competência e construção prévia como autoridade o autorizavam para a formação de quadros profissionais e agentes capacitados para a tarefa de administrar refugiados. Essa nova competência administrativa, conforme a proposta de Souza Lima, permite um exercício de soberania sobre os territórios de um Estado que se diz nacional, já que, com a produção e administração dos refugiados, cria-se concomitantemente a fronteira que se deseja proteger. Tudo isso por meio de dispositivos que não necessariamente exigem um grande investimento em recursos humanos ou materiais.

De fato, a participação de ONGs da chamada "sociedade civil" tem desempenhado um papel central assumindo alguns dos compromissos sociais derivados da recepção de refugiados e, além disso, boa parte de seu financiamento e planejamento tem se deixado nas mãos do Acnur. No universo brasileiro do refúgio, essa isenção de responsabilidades pareceria não haver debilitado o poder estatal nesse espaço de gestão de populações, nem ter afetado a percepção das pessoas nele envolvidas acerca do Estado como um agente político concreto. Ao contrário, esse formato de ação pareceria alimentar a percepção comum do Estado "como uma estrutura diferente das agências e das estruturas na sociedade nas quais opera" (Abrams, 1988 p. 80), apontando que as formas e os exercícios das práticas políticas são os que, em grande parte, permitem tal caracterização.

\section{Bibliografia}

ABRAMS, Philip. "Notes on the Difficulty of Studyng the State", en Scharma y Gupta, The Anthropology of the State. A reader, Balckwell Publishing, pp. 112-130, 2004.

ANZALDUA, Gloria. Borderlans/La frontera The new mestiza. Tradução Carmen Valle, Capitán Swing: Madrid, 2016. 
BETANCUR, María Soledad, "Del estatuto de seguridad al estado comunitario: veinticinco años de criminalización de la protesta social en Colombia" In: Movimientos sociales y gobiernos en la región andina - Resistencias y alternativas. Lo político y lo social. Buenos Aires: Observatorio Social de América Latina, Consejo Latinoamericano de Ciencias Sociales, p. 179-185, Año VII, N 19, enero-abril, 2006.

BOLTANSKI, Luc. La Souffrance a Distance: morale humanitaire, médias et politique. Paris: Métailié, Collection Leçons de choses, 1993.

CHO, Grace. Haunting the Korean Diaspora: Shame, secrecy and the forgotten war. Minneapolis: University of Minnesota Press, 2008.

DAS, Veena. "Trauma y testimonio". In: Ortega, Francisco (Ed). Sujetos de dolor, agentes de dignidad. Bogotá: Universidad Nacional de Colombia, Colección Lecturas CES, p. 145169, 2008.

DAS, Venna \& POOLE, Deborah. "State and its margins: comparative ethnographies", In: Venna Das y Deborah Poole. Anthropology in the Margins of the State. Santa Fe: School of American Research Press, pp. 3-33, 2004.

FACUNDO, Angela. Êxodos, refúgios e exílios. Rio de Janeiro: Papeis Selvagens, 2017.

FOUCAULT, Michel. "El sujeto y el poder”. In: Revista Mexicana de Sociología, México, v. 50, n. 3, p. 3-20, jul./sep., 1988.

HAMID, Sonia. (Des) Integrando Refugiados: Os Processos do Reassentamento de Palestinos no Brasil. Tese doutoral. Universidade de Brasília, programa de Pós-Graduação em Antropologia Social, 2012.

HERZFELD, Michael. The social production of the indifference. Exploring the symbolic roots of Western bureaucracy. Chicago: University of Chicago Press, 1992.

JARDIM, Denise Fagundes. "Palestinos: as redefinições de fronteiras e cidadania". In: Horizontes Antropológicos, Jul, vol.9, no.19, p.223-243, 2003.

MALKKI, Liisa. Purity and exile: violence, memory, and national cosmology among Hutu refugees in Tanzania. Chicago: University of Chicago Press, 1995.

MITCHELL, Timothy. "sociedad, economía y el efecto Estado". In: Abrams; Gupta \& Mitchell (eds.) Antropología del Estado. México: Fondo de Cultura Económica, pp. 145$183,2015$.

MOULIN, Carolina. "Os direitos humanos dos humanos sem direitos: refugiados e a política do protesto". In: Revista brasileira de Ciências Sociais, Jun, vol.26, no.76, p.145$155,2011$.

PERIN, Vanessa. "Um campo de refugiados sem cercas": etnografia de um aparato de governo de populações refugiadas. Horizontes Antropológicos, Porto Alegre, v. 20, n. 41, p. 303-330, June 2014.

POLLAK, Michael. L'expérience concentrationnaire. Essai sur Le maintien de l'identité sociale. Paris: Éditions Métailié, 1990. 
RADHAY, Rachael. Discurso e poder na política da imigração brasileira. Tese de doutorado em linguística, Universidade de Brasília, UNB, 2006.

RAMIREZ, María Clemencia. Entre el Estado y la guerrilla: identidad y ciudadanía en el movimiento de los campesinos cocaleros del Putumayo. Bogotá: ICANH, 2001.

SAYAD, Abdelmalek. L'immigration ou les paradoxes de l'altérité. Bruxelles: De Boeck Université; Paris: Universitaires, 1991.

SEYFERTH, Giralda. "Assimilação dos Imigrantes no Brasil: Inconstâncias de um Conceito Problemático”. In: Revista Travessia, São Paulo, v. 36, p. 44-50, 2000.

SOUZA LIMA, Antonio. Um grande cerco de paz: poder tutelar, indianidade e formação do Estado no Brasil. Petrópolis: Vozes, 1995.

SOUZA LIMA, Antonio. "O exercício da tutela sobre os povos indígenas: considerações para o entendimento das políticas indigenistas no Brasil contemporâneo". In: Revista de Antropologia da USP, São Paulo, v. 55, n. 2, 2012.

TROUILLOT, Michel-Rolph. "The anthropology of the state in the age of globalization. Close encounters of the deceptive kind". In: Current Anthropology, v. 42, n. 1, p. 125-138, 2001.

VIANNA, Adriana. Limites da menoridade: tutela, família e autoridade em julgamento. Tese doutoral, Universidade Federal do Rio de Janeiro, Museu Nacional, Programa de PósGraduação em Antropologia Social, 2002.

VIANNA, Adriana; FACUNDO, Ángela. "Tempos e deslocamentos na busca por justiça entre "moradores de favelas" e "refugiados"'”. In: Revista Ciência e cultura, São Paulo, v. 67, n. 2, p. 46-50, June, 2015.

VIEIRA, Rosa. "O governo da mobilidade Haitiana no Brasil”. In: Revista Mana, Jan, vol.23, no.1, p.229-254, 2017.

\section{Deslocamento Forçado na Colômbia e Políticas de Refúgio no Brasil: Gestão de populações em êxodo}

\section{Resumo}

Baseado numa pesquisa de cunho etnográfico sobre processos de refúgio de nacionais colombianos no Brasil, o articulo discute práticas e formatos de produção e gestão de sujeitos refugiados no governo contemporâneo de populações em êxodo. O trabalho argumenta que a precariedade das políticas públicas não é equivalente a uma ausência do poder do Estado para produzir sujeitos expulsáveis e/ou para filtrar aqueles que serão reconhecidos, daqueles que serão encaixados em outras categorias migratórias ou deixados de fora. Numa perspectiva antropológica, a partir do que poderíamos denominar de uma etnografia do Estado o texto leva a sério o não fazer e o fazer precário como poderosas forças de ação política, expondo, de forma concreta, algumas práticas das tradições administrativas brasileiras na gestão de refugiados que foi possível identificar na pesquisa de campo.

Palavras chave: Refúgio, Reassentamento, Colômbia, Brasil

\section{Forced Displacement in Colombia and Refuge Policies in Brazil: management of populations in exodus}

Abstract

Revista de Estudos e Pesquisas sobre as Américas V.13 N.1 2019 ISSN: 1984-1639 
Based on an ethnographic research on refugee processes of Colombian nationals in Brazil, the article discusses practices and formats of production and management of subjects in the contemporary government of populations in exodus. The paper argues that the precariousness of public policies is not tantamount to an absence of state power to produce excludable subjects and / or to filter out those who will be recognized and those who will be embedded in other migratory categories or left out. From an anthropological perspective, from what we might call an ethnography of the State, the text takes seriously the failure to do and make it precarious as powerful forces of political action, exposing, in a concrete way, some practices of the Brazilian administrative traditions in the management of refugees that it was possible to identify in field research.

Keywords: Refuge, Resettlement, Colombia, Brazil

\section{Desplazamiento en las Políticas de Colombia y el Refugio en Brasil Forzado: manejo de poblaciones en Éxodo}

\section{Resumen}

Con base en una investigación de carácter etnográfico sobre procesos de refugio de nacionales colombianos en el Brasil, el presente artículo discute prácticas y formatos de producción y administración de sujetos en el gobierno contemporáneo de poblaciones en éxodo. El trabajo argumenta que la precariedad de las políticas públicas no es equivalente a la ausencia del poder del Estado para producir sujetos expulsables y/o para filtrar a aquellos que serán reconocidos de aquellos que serán encajados en otras categorías migratorias o dejados fuera. En una perspectiva antropológica, a partir de una etnografía del Estado, el texto se toma en serio el no hacer y el hacer precariamente como poderosas fuerzas de acción política, presentando, de forma concreta, algunas prácticas de las tradiciones administrativas brasileñas para la gestión de refugiados que fue posible identificar en la investigación de campo.

Palabras clave: Refugio, Reasentamiento, Colombia, Brasil 